\title{
DNA TARGETING AS A MOLECULAR MECHANISM UNDERLYING ENDOGENOUS INDOLES BIOLOGICAL EFFECTS
}

\author{
CRISTINA MANUELA DRĂGOI ${ }^{1}$, ALINA CRENGUŢA NICOLAE ${ }^{1 *}$, ION-BOGDAN \\ DUMITRESCU ${ }^{2}$, DANIELA ELENA POPA ${ }^{3}$, MIRELA RITIVOIU ${ }^{4}$, ANDREEA LETIŢIA \\ ARSENE $^{5}$ \\ ${ }^{I}$ Department of Biochemistry, Faculty of Pharmacy, "Carol Davila" University of Medicine and Pharmacy, Bucharest, Romania \\ ${ }^{2}$ Department of Physics and Informatics, Faculty of Pharmacy, "Carol Davila" University of Medicine and Pharmacy, \\ Bucharest, Romania \\ ${ }^{3}$ Department of Drug Control, Faculty of Pharmacy, "Carol Davila” University of Medicine and Pharmacy, Bucharest, Romania \\ ${ }^{4}$ Department of Paediatrics, Faculty of Medicine, "Alessandrescu-Rusescu”" INSMC, "Carol Davila” University of Medicine \\ and Pharmacy, Bucharest, Romania, \\ ${ }^{5}$ Department of Microbiology, Faculty of Pharmacy, "Carol Davila” University of Medicine and Pharmacy, Bucharest, Romania
}

*corresponding author: alina.nicolae@umfcd.ro

Manuscript received: December 2018

\begin{abstract}
The present study aimed to investigate the potential intra-nuclear signalling mechanism of the endogenous bioindoles: melatonin, serotonin and tryptophan, through their direct interaction with the DNA. The DNA-indoles interaction has been studied in vitro by using a spectrofluorometric method, determining the intensity of the fluorescent signal issued by the indole molecules, natively fluorescent, in the presence of the DNA, molecule which lacks fluorescence. The experimental results highlighted a decrease of the fluorescent signal of the indoles under analysis, in the presence of DNA, proving an in vitro direct interaction the double-stranded DNA quenching the fluorescent signal of the studied endogenous molecules. This masking effect could be due to their intercalation in the double helix DNA structure. The results were significantly higher in the case of DNA-melatonin interaction compared to serotonin $(p<0.0001)$ and tryptophan $(p<0.0001)$, respectively. The quenching of the florescent signals of DNA-indole systems were evaluated through the Stern-Volmer constants $\left(\mathrm{K}_{\mathrm{SV}}\right)$. Further on, the type of DNA-indoles bonds has been assessed by means of ethidium bromide (EB) studies and UV spectroscopy was used in order to calculate the binding constants.
\end{abstract}

\section{Rezumat}

În studiul de față s-a urmărit investigarea potențialelor mecanisme de semnalizare intra-nucleară a bioindolilor endogeni: melatonina, serotonina şi triptofanul, prin interacțiunea lor directă cu ADN-ul. Interacțiunea ADN-indoli a fost studiată in vitro spectrofluorimetric, determinând intensitatea semnalului fluorescent emis de moleculele de indol, nativ fluorescente, în prezența moleculei de ADN care nu dezvoltă fluorescență. Rezultatele experimentale au evidențiat o scădere a semnalului fluorescent al indolilor analizați, în prezența $\mathrm{ADN}$-ului, demonstrând existența in vitro a interacțiunilor directe între moleculele cu structură indolică şi ADN-ul dublu catenar din timus de viţel, ceea ce are ca rezultat stingerea semnalului fluorescent al moleculelor endogene studiate. Acest efect de mascare ar putea fi datorat intercalării lor în structura de dublu helix a ADN-ului. Stingerea semnalului fluorescent în cazul interacțiunii ADN-melatonină a fost semnificativ mai mare, comparativ cu serotonina $(\mathrm{p}<0,0001)$ şi, respectiv, triptofanul $(\mathrm{p}<0,0001)$. Interacțiunea ADN-indoli a fost evaluată matematic prin calcularea constantelor Stern-Volmer $\left(\mathrm{K}_{\mathrm{SV}}\right)$. În continuare, tipul de legătură ADN-indoli a fost evaluat prin intermediul studiilor cu bromura de etidiu (EB), iar analiza spectrală UV a permis calcularea constantelor de legare.

Keywords: DNA, intercalation, ethidium bromide, melatonin, serotonin, tryptophan, indole, Stern-Volmer

\section{Introduction}

Deoxyribonucleic acid (DNA) is the primary intramolecular target for a wide range of therapeutic endogenous or exogenous substances, whose base sequence controls the heredity of life, acting as cellular receptor. This is due to the existence of interactions between DNA and small-sized molecules (ligands) [16, 21, 26]. The DNA structure presents numerous binding sites both for the intracellular constituents and for xenobiotics. The binding of various structures at the DNA level is essential for the adjustment of some highly important processes: transcription, replication and the expression of genetic information in cells, and thereby influence its physiological function and inhibiting the growth of tumour cells, which is the basis for more effective 
FARMACIA, 2019, Vol. 67, 2

drug design $[2,3,5,6]$. Nevertheless, DNA interaction with several compounds fixed at the level of specific sites of the DNA structure is the starting point of some processes inducing the reversible or irreversible degradation of nucleic acids. Therefore, the study of the interaction between drugs or endogen key molecules and DNA plays a key role in elucidating biochemical mechanisms of action and it is of great significance for the synthesis of new therapeutic molecules targeted to DNA [1, 15, 20-23, 28-30]. In cancer therapy, small molecules are synthesized for binding to various parts of DNA by groove binding, via intercalation, cross-linking or even DNA strandscission $[10,13]$.

The literature describes some mechanism whereby the DNA-ligand interaction can occur: intercalation of the ligand between the nitrogenous bases pairs (simple interaction process and bis-intercalation); interactions with the DNA cavities; electrostatic interactions with the DNA external skeleton [2].

Natural products are small molecules that present the potential to form molecular complexes with DNA by groove binding or intercalation, with relatively low toxicity $[14,18]$. Indole is a heterocyclic compound with characteristic properties due to the presence of an electron-rich pyrrole moiety that can interact non-covalently with other molecules by formation of hydrogen bonding in the NH moiety. Due to this property, indole ring is widely studied for the development of newer biologically active derivatives, since it is a constituent of proteins in the form tryptophan residues, and has a wide range of pharmacological activities [7-9, 16-19].

The study of the interactions between DNA and endogenous molecules with an indole structure is of utmost importance for the understanding of their molecular mechanisms. Tryptophan, serotonin and melatonin are endogenous biomolecules with an indole core, bearing complex biological implications.

Particularly, melatonin is a bio-indole with a high degree of lipophilia, which favours its transmembrane transport at all intracellular levels. A possible melatonin signalling nuclear path could account for some of the various effects of this hormone, at the level of the endocrine, immune or nervous systems [28]. One of the hypotheses issued on this topic implies the existence of a nuclear specific mechanism of action, sustained by the melatoninergic-specific receptors, ML1, ML2, ML3, present at the nuclear level [25, 27, 28].

Tryptophan is an essential amino acid constituent of many endogenous proteins, being at the same time a precursor in the serotonin (5- hydroxytryptamine, 5HT) synthesis. Low serum concentrations of tryptophan have been clinically correlated with the occurrence of infectious, autoimmune and tumorigenesis mechanisms [4, 24].
Serotonin is a neurotransmitter and a hormone with indolic structure, with major biological effects generally by coordinating the activity of the nervous system, mostly on determining the type of behaviour, such as appetitive, emotional, motor, cognitive and autonomic $[11,12]$. The misbalances in the serotoninergic metabolism determine the ethology and the pathophysiology of neuro-psychiatric and systemic disorders, including the development of serotonin-secreting tumours.

Therefore, the reveal of new biochemical facets of tryptophan, serotonin and melatonin as well as their relations and interactions with other vital biomolecules, as is the case of DNA, the more we may contribute to the understanding and optimising the therapeutic approach of several auto-immune, psychiatric conditions and of neoplastic processes.

In this complex pathophysiologic context, yet to be fully clarified, we aimed to investigate the potential intra-nuclear signalling mechanism of the endogenous indoles (melatonin, serotonin and tryptophan) through their direct interaction with the DNA. The DNAindoles interaction has been studied in vitro by using a spectrofluorometric method, determining the intensity of the fluorescent signal issued by the indole molecules, natively fluorescent, in the presence of the DNA, molecule which does not develop fluorescence. Further on, the exact type of DNA-indoles bond has been determined by means of ethidium bromide (EB) studies, an important intercalating agent in the DNA molecule and, at the same time, a highly useful fluorescent probe for DNA assessment, considering that, if a compound interacts through intercalation with the double-stranded DNA structure, it is registered a decrease of the fluorescent signal of the DNA-EB system by over $40 \%[6,23]$.

The determined indoles-DNA interactions have been also UV spectroscopically assessed in view of computing the binding constants of the indole molecules to the double-stranded calf thymus DNA. All registered data were meant to characterize in detail the DNAindoles interactions at the nuclear level.

\section{Materials and Methods}

Reagents: all reagents were commercially available and were used without further purification. Melatonin, serotonin, tryptophan, double-stranded calf thymus DNA, ethidium bromide, TRIS buffer, dimethyl sulfoxide were purchased from Sigma-Aldrich.

Equipments: LS50 B Perkin Elmer spectrofluorimeter, Cary 100 Bio (Varian Inc.) UV-VIS spectrophotometer equipped with thermostated cell holder and magnetic stirring.

Preparation of the double-stranded DNA solution from calf thymus, concentration $1.656 \times 10^{-4} \mathrm{M}$. The solution was prepared in TRIS buffer and refrigerated 
FARMACIA, 2019, Vol. 67, 2

for 24 hours at a temperature of $4^{\circ} \mathrm{C}$. After 24 hours the precise concentration of the obtained DNA solution was determined. This has been performed by using the spectrometric method, by reading the absorbances in $\mathrm{UV}$, at $\lambda=260 \mathrm{~nm}$, of the prepared double-stranded DNA solution from calf thymus (the extinction molar coefficient of the DNA at $260 \mathrm{~nm}$ is $\varepsilon=6600 \mathrm{M}^{-1} \mathrm{~cm}^{-1}$ ).

It was also registered the absorbance of the same solution at $\lambda=280 \mathrm{~nm}$, in order to quantify the protein content. The obtained absorbance ratio in $\mathrm{UV}$ at $260 \mathrm{~nm}$ and $280 \mathrm{~nm}$ was 1.88 , which indicated that the prepared DNA solution has a sufficiently low content of proteins and can be used in the experimental study.

Preparation of the working solution for each studied indole (melatonin, serotonin, tryptophan, commercially available), in a concentration equivalent with the concentration of the DNA solution $\left(1.656 \times 10^{4} \mathrm{M}\right)$. The solvent for serotonin and tryptophan solutions was TRIS buffer $\mathrm{pH}=7$. For the melatonin solution, the substance has been initially solubilized in the minimum volume of DMSO (dimethyl sulfoxide) and then brought to $10 \mathrm{~mL}$ with TRIS buffer $\mathrm{pH}=7$.

Interactions between DNA and the three indole compounds have been evaluated using various samples following the DNA/indole molar ratios: 1:1, 2:1, 3:1, $4: 1,5: 1,6: 1,7: 1,8: 1,9: 1,10: 1$. The fluorescence spectra have been immediately recorded, at the following wavelengths: melatonin: $\lambda_{\text {excitation }}=280 \mathrm{~nm}$ and $\lambda_{\text {emission }}=354 \mathrm{~nm}$; serotonin: $\lambda_{\text {excitation }}=280 \mathrm{~nm}$

and $\lambda_{\text {emission }}=338 \mathrm{~nm}$; and tryptophan: $\lambda_{\text {excitation }}=$ $280 \mathrm{~nm}$ and $\lambda_{\text {emission }}=362 \mathrm{~nm}$.

Preparation of the ethidium bromide (EB) solution, concentration $1 \times 10^{-5} \mathrm{M}$. The solution was obtained by dissolving EB in the TRIS buffer solution $\mathrm{pH}=7$. The type of interactions between DNA and the three indole substances has been evaluated as follows: we initially obtained the DNA-EB complex by putting in direct contact the EB and doublestranded DNA solution in the reading cell of the spectrofluorometer, in equal quantities $(100 \mu \mathrm{L}$ DNA $+100 \mu \mathrm{L}$ EB). Then, we added increasing volumes of the studied indole solutions, obtaining the following indole/DNA molar rations: $1: 1,2: 1$, $3: 1,4: 1,5: 1,6: 1,7: 1,8: 1,9: 1,10: 1$. The spectra have been immediately registered under magnetic agitation in the reading cell, at the same previously mentioned wavelengths.

The UV absorption spectra of the DNA have been recorded in the $200-400 \mathrm{~nm}$ range. The samples absorbance has been read at $\lambda=260 \mathrm{~nm}$.

For each molar ratio, we performed 10 replicates. The results are presented as means \pm standard deviation. Statistical analysis

Statistical significance was determined using the SPSS software. Significance was set at $\mathrm{p} \leq 0.05$.

\section{Results and Discussion}

Table I shows the experimental data obtained following the in vitro evaluation of DNA-indoles interactions, for the employed DNA/indole molar rations (1:1, $2: 1,3: 1,4: 1,5: 1,6: 1,7: 1,8: 1,9: 1,10: 1)$.

Table I.

Variation of the fluorescent signal for different DNA-indole ratios

\begin{tabular}{cccc}
\hline $\begin{array}{c}\text { DNA/indoles } \\
\text { molar ratio }\end{array}$ & $\begin{array}{c}\text { Relative fluorescence intensities (r.f.u.) } \\
\text { of DNA/melatonin complexes (mean } \pm \\
\text { SD) }\end{array}$ & $\begin{array}{c}\text { Relative fluorescence intensities (r.f.u.) } \\
\text { of DNA/serotonin complexes (mean } \pm \\
\text { SD) }\end{array}$ & $\begin{array}{c}\text { Relative fluorescence intensities (r.f.u.) } \\
\text { of DNA/tryptophan complexes (mean } \pm \\
\text { SD) }\end{array}$ \\
\hline $1: 1$ & $85.12 \pm 6.91$ & $44.51 \pm 3.63$ & $42.43 \pm 3.04$ \\
$2: 1$ & $83.68 \pm 6.13$ & $41.65 \pm 3.12$ & $40.75 \pm 3.29$ \\
$3: 1$ & $78.71 \pm 6.29$ & $37.01 \pm 2.99$ & $39.14 \pm 3.72$ \\
$4: 1$ & $75.34 \pm 6.81$ & $35.12 \pm 2.82$ & $38.51 \pm 3.04$ \\
$5: 1$ & $73.21 \pm 6.02$ & $32.43 \pm 2.71$ & $36.68 \pm 3.11$ \\
$6: 1$ & $68.87 \pm 5.29$ & $30.06 \pm 2.49$ & $34.82 \pm 2.74$ \\
$7: 1$ & $64.33 \pm 5.11$ & $28.71 \pm 2.28$ & $33.47 \pm 2.51$ \\
$8: 1$ & $62.99 \pm 4.28$ & $30.56 \pm 2.96$ & $33.98 \pm 2.84$ \\
$9: 1$ & $60.09 \pm 4.93$ & $28.44 \pm 2.04$ & $29.4 \pm 2.73$ \\
$10: 1$ & $56.42 \pm 4.35$ & $29.04 \pm 2.36$ & $29.24 \pm 2.56$ \\
\hline
\end{tabular}

Figure 1 shows representative fluorescence spectra obtained during the indoles-DNA interactions study. 


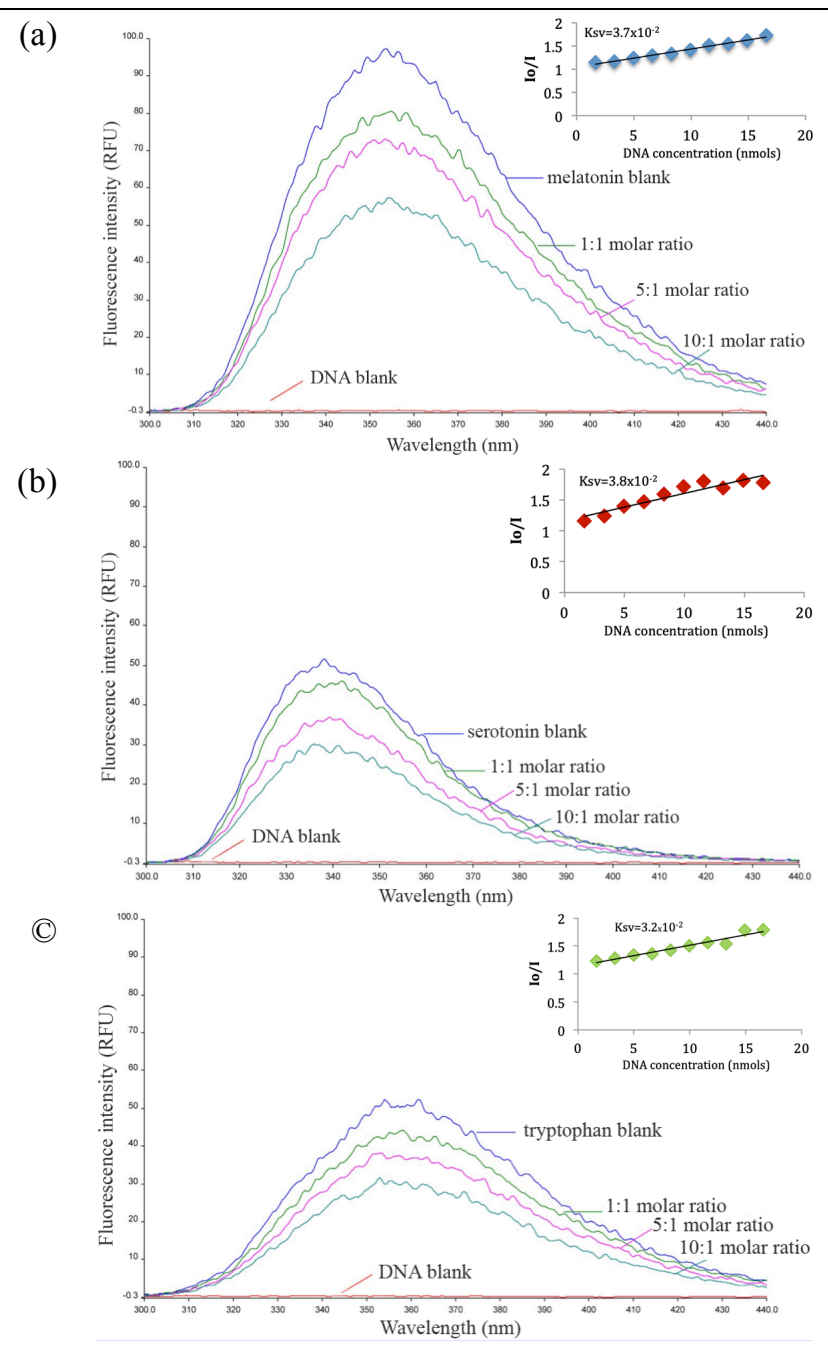

Figure 1.

Fluorescence spectra obtained in the interaction study of DNA-melatonin (a), DNA-serotonin (b), DNAtryptophan (c). The figures present the spectra obtained for the indole control, DNA control and samples of DNA-indole complexes in molar ratios 1:1, 5:1 and 10:1. Inset: Stern-Volmer graphs of fluorescence quenching

Figure 2 presents, in a comparative manner, the dynamics of the studied DNA-indoles interaction processes. The studied indoles are endogenous biomolecules with native fluorescence, which develop a significant fluorescent signal, while the DNA molecules do not develop fluorescence. In the experiment, we observed that the DNA in increasing concentrations, added to a constant indole concentration, developed decreasing fluorescence signals. This phenomenon could be due to the quenching of the fluorescent signal of the indoles molecules. The quenching phenomenon suggests a "masking" of the native fluorescence of the indole. It is likely that such a phenomenon is due to an intercalation process of the indole inside the double strand structure of DNA. Therefore, the indole's fluorescence diminishes despite its constant concentration in the sample. It has been observed that the interaction of melatonin with the double-stranded DNA molecules is the most pronounced. The quenching of the fluorescence signal in the DNA-melatonin interaction has been significantly higher, in comparison with serotonin $(\mathrm{p}<0.0001)$ and tryptophan $(\mathrm{p}<0.0001)$, respectively.

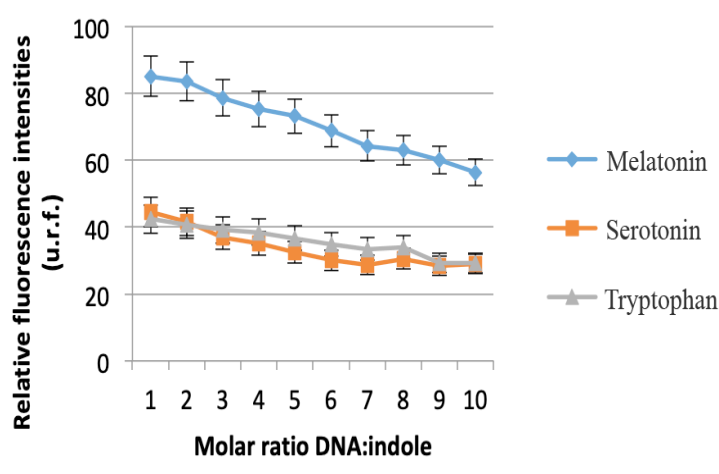

Figure 2.

Dynamics of DNA-indoles interaction processes depending on the employed DNA-indole molar ratio

The studied interactions are characterised by higher fluorescence signals for melatonin compared to serotonin and tryptophan. Analysing the dynamics of 
FARMACIA, 2019, Vol. 67, 2

the fluorescent signal quenching processes, we may argue that serotonin and tryptophan displayed a similar behaviour, registering close values of fluorescence intensities.

The dynamics of these biochemical processes has been statistically evaluated using the SPSS software, calculating the Pearson coefficients characterising the obtained experimental results: DNA/melatonin interaction - Pearson coefficient $r=-0.9646$; DNA/ serotonin interaction - Pearson coefficient $r=-0.91987$; DNA/tryptophan interaction - Pearson coefficient $r=-0.9847$. As it can be observed, for the 3 indoles, there is a negative statistical correlation of these parameters. According to the obtained data, the value of the correlation coefficients, in absolute value, varies as follows:

$$
r_{\text {melatonin }}>r_{\text {tryptophan }}>r_{\text {serotonin }}
$$

These results indicate a higher affinity of the melatonin molecules to form bonds with the double-stranded DNA structure, compared to tryptophan and serotonin, respectively.

The DNA-indole interactions have been also studied in terms of the temporal dynamics. As such, we used the DNA-indole molar ratio $10: 1$, for which the highest value of the fluorescent signal has been registered, i.e. the most powerful interaction. We assessed the indoles' interaction with the doublestranded calf thymus DNA, at different time intervals $(0,15,30,45,60$ minutes $)$.

The obtained results, graphically represented in Figure 5 , reveal that these interactions are stable over time. There have been no significant time driven modifications of the fluorescence signals of the analysed samples. Figure 3 shows representative spectra obtained during the study of the temporal dynamics of DNA-indoles interaction.

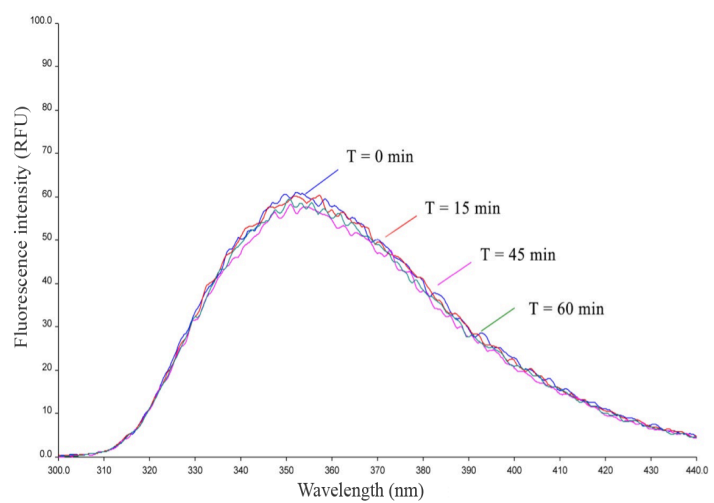

Figure 3.

Representative fluorescence spectra for the study of the temporal dynamics of DNA-melatonin interactions



Figure 4.

Temporal dynamics of DNA-indoles interactions

The DNA-indole interactions have been evaluated mathematically by computing the quenching constants of the fluorescent signal, using the Stern-Volmer equation:

$$
\mathrm{I}_{0} / \mathrm{I}=1+\mathrm{K}_{\mathrm{SV}}[\mathrm{DNA}]
$$

where, $\mathrm{I}_{0}=$ fluorescence intensities without DNA, I = fluorescence intensities with DNA, $\mathrm{K}_{\mathrm{SV}}=$ Stern-Volmer quenching constant, [DNA] = DNA concentration.

The DNA concentration variation was graphically represented depending on the fluorescence intensities ratio in the absence and in the presence of DNA (Io/I) and we obtained the Stern-Volmer graphics (Inset of Figure 1).

We observed an increase of the fluorescence quenching phenomenon for all 3 studied indole molecules, along with the increase of the DNA concentration. The calculation of Stern-Volmer constant has been made by relating the slope to the equation tangent describing the fluorescence quenching process. The experimental results led to the following values of Stern-Volmer quenching constant $\left(\mathrm{K}_{\mathrm{SV}}\right)$ : DNA/melatonin interaction: $\mathrm{K}_{\mathrm{SV}}=3.7 \times 10^{-2}$; DNA/serotonin interaction: $\mathrm{K}_{\mathrm{SV}}=$ $3.8 \times 10^{-2}$; DNA/tryptophan interaction: $\mathrm{K}_{\mathrm{SV}}=3.2 \times 10^{-2}$. As such, the $\mathrm{K}_{\mathrm{SV}}$ values for the three interacting systems (DNA-melatonin, DNA-serotonin, DNAtryptophan) have been extremely close from a numeric standpoint, which suggests the major contribution of the indole ring in the intercalation phenomenon of the studied endogen molecules between the DNA nitrogenous bases pairs.

The fluorescence quenching is a process which decreases the intensity of the fluorescent signal issued by the analysed sample. The literature describes 2 major processes of fluorescence quenching that can also take place simultaneously in the same sample: dynamic fluorescence quenching and static fluorescence quenching [30, 32]. The dynamic fluorescence quenching is due to a diffusion process between the fluorophore agent (indole molecules) and the molecules triggering the florescence quenching (DNA). The diffusion takes place during the excitation period and the fluorophore resumes to its basal state without issuing photons. The static fluorescence quenching 
is due to the formation of a complex between the indole and DNA, a non-fluorescent complex. The registered fluorescent signal is diminished due to the indole molecules which do not participate in the formation of the DNA-indole complex. In the scientific literature, the bio-physical and chemically issued phenomenon of fluorescence quenching of certain compounds is called "masking" of the fluorescent signal. As such, Yumin et al. proved the quenching of Morin (antineoplastic agent) fluorescence after the direct DNA interaction [31]. Similar results have also been reported by Wei et al. following in vitro research on the interactions of gatifloxacin mesylate compounds (antibiotics from the fluoroquinolone class) and Mitoxantron (anti-tumour drug) with the DNA. It has been concluded that the masking of the fluorescent signal is due to an intercalation process of the studied compounds inside the DNA double strand [30].

The linearity of the graphs obtained in the assessment of the indoles-DNA interactions and the Stern-Volmer constants values reveal the existence of a single fluorophore agent, namely the indole molecules, in the analysed samples and prove the existence of a direct connection between DNA and the studied bio-indoles, as well as the affinity thereof for the formation of specific bonds with the DNA structure, process followed by the quenching of the samples' fluorescence.
Fluorometric ethidium bromide intercalating studies for depicting the DNA-indole interactions

The exact type of DNA-indoles bonds has been studied using a fluorometric method by means of ethidium bromide (EB), an important intercalating agent in the double-stranded DNA molecule and, at the same time, a highly useful fluorescent probe for DNA studies. As such, if the binding of the indole molecules to the DNA structure is made in the same way as the binding of the ethidium bromide (EB), we witness the indoles "competing" phenomenon with the ethidium bromide (EB). Through the displacement of EB molecules fixed in the DNA structure and their replacement with the studied indole derivatives, we observe a decrease in the intensity of the fluorescent signal issued by the DNA-EB system, along with the increase of the indole concentration added in the system. The scientific literature states that a compound interacts through intercalation with the double-stranded DNA structure, if it is registered a decrease over $40 \%$ of the fluorescent signal issued by the DNAEB system [20, 22, 32].

Table II shows the obtained fluorescence intensities following the addition of increasing concentrations of indoles, depicted by the resulting indole/DNA molar ratio.

Dynamics of the relative fluorescence intensities registered by the DNA-EB system after adding increasing indole concentrations in the system

\begin{tabular}{cccc}
\hline $\begin{array}{c}\text { Indole / DNA } \\
\text { molar ratio }\end{array}$ & $\begin{array}{c}\text { Relative fluorescence } \\
\text { intensities (r.f.u.) of DNA-EB } \\
\text { complex after adding melatonin } \\
\text { (mean } \pm \text { SD) }\end{array}$ & $\begin{array}{c}\text { Relative fluorescence intensities } \\
\text { (r.f.u.) of DNA-EB complex } \\
\text { after adding serotonin } \\
\text { (mean } \pm \text { SD) }\end{array}$ & $\begin{array}{c}\text { Relative fluorescence intensities } \\
\text { (r.f.u.) of DNA-EB complex after } \\
\text { adding tryptophan } \\
\text { (mean } \pm \text { SD) }\end{array}$ \\
\hline ADN-EB complex & $375.11 \pm 18.19$ & $204.41 \pm 9.74$ & $281.29 \pm 10.43$ \\
\hline DNA blank & $0.36 \pm 0.02$ & $0.36 \pm 0.02$ & $0.36 \pm 0.02$ \\
\hline EB blank & $45.67 \pm 0.82$ & $45.67 \pm 0.82$ & $45.67 \pm 0.82$ \\
\hline DNA-indole complex & $79.98 \pm 5.32$ & $44.51 \pm 2.87$ & $42.43 \pm 2.15$ \\
\hline Indole solution & $97.3 \pm 6.49$ & $51.64 \pm 3.73$ & $52.28 \pm 4.07$ \\
\hline $1: 1$ & $112.25 \pm 8.14$ & $104.94 \pm 8.21$ & $103.58 \pm 8.73$ \\
$2: 1$ & $103.24 \pm 7.95$ & $97.02 \pm 7.54$ & $102.26 \pm 8.02$ \\
\hline $3: 1$ & $88.4 \pm 6.14$ & $86.88 \pm 7.03$ & $85.65 \pm 6.48$ \\
$4: 1$ & $81.18 \pm 6.93$ & $75.17 \pm 6.21$ & $80.42 \pm 6.19$ \\
\hline $5: 1$ & $74.82 \pm 5.84$ & $67.07 \pm 5.48$ & $73.35 \pm 5.28$ \\
$6: 1$ & $72.46 \pm 6.18$ & $56.96 \pm 4.29$ & $68.11 \pm 5.04$ \\
\hline $7: 1$ & $68.26 \pm 5.32$ & $50.96 \pm 3.96$ & $63.17 \pm 4.99$ \\
$8: 1$ & $66.1 \pm 5.21$ & $44.41 \pm 3.27$ & $60.02 \pm 4.18$ \\
$9: 1$ & $62 \pm 4.85$ & $40.1 \pm 2.94$ & $59.4 \pm 3.79$ \\
$10: 1$ & $60.1 \pm 4.63$ & $39.61 \pm 2.76$ & $58.11 \pm 3.62$ \\
\hline
\end{tabular}

Ethidium bromide $(\mathrm{EB})$ is a typical intercalation agent in the double-stranded DNA molecule and, at the same time, a fluorescent probe issuing a powerful fluorescent signal. The three studied indoles are endogenous biomolecules with native fluorescence which develop a significant fluorescent signal, while 
the DNA molecules do not exhibit fluorescence. Therefore, if the binding of the indole molecules to the DNA structure is performed similarly to $\mathrm{EB}$, the "competition" of the indole with the EB occurs, leading to the decrease of the fluorescent signal intensity of the studied system.

The experimental results showed that ethidium bromide (EB), in buffer solution, presents a fluorescence signal of moderate intensity (45.67 \pm 0.82 r.f.u.), due to the quenching of the EB fluorescence by the solvent molecules. The melatonin solution presents a high level of fluorescence $(97.3 \pm 6.49$ r.f.u.). After adding the double-stranded DNA solution to the EB solution, we observe a sudden, significant increase of the system's fluorescence intensity. This is due to the powerful intercalation process of the EB molecules between the DNA nitrogenous bases pairs [23].
By adding melatonin solution to the DNA-EB compound, this forms more powerful links than EB, to the DNA. We thus observe a considerable decrease of the fluorescent signal. This fluorescence quenching process points the existence of a competition between melatonin and EB, for DNA bonding. The decrease of the fluorescent signal of the DNA-EB complex is due to the displacement of the EB molecules by melatonin and the firm positioning of the indole molecule between the DNA nitrogenous bases pairs, through an intercalation process (Figure $5 \mathrm{a}$ ).

Regarding the interactions of serotonin and tryptophan, we found the same dynamics of the intercalation process of these indole molecules in the doublestranded DNA structure as in the case of melatonin (Figure $5 b$ and $5 c$ ).

(a)

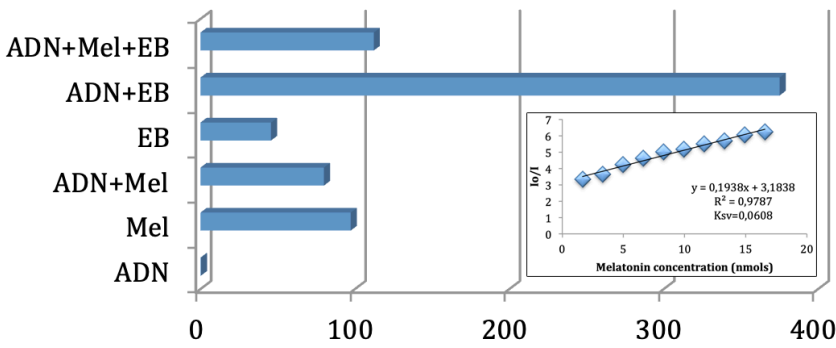

Relative fluorescence units(RFU)

(b)

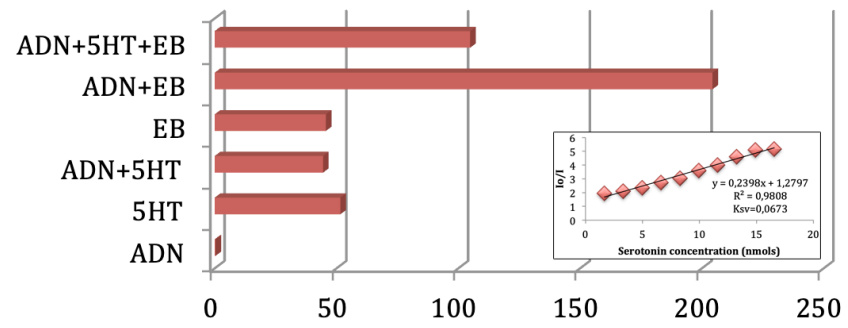

Relative fluorescence units(RFU)

(c)

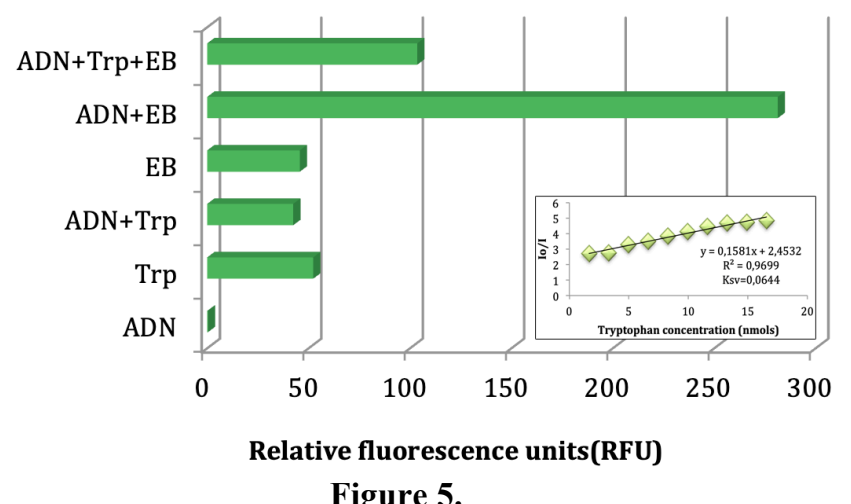

Variations of the relative fluorescence intensities in the DNA-EB-indoles system

(a - DNA-EB-melatonin, b - DNA-EB-serotonin, c - DNA-EB-tryptophan; where DNA = deoxyribonucleic acid, EB = ethidium bromide, $\mathrm{Mel}=$ melatonin, $5 \mathrm{HT}=$ serotonin, $\operatorname{Trp}=$ tryptophan). Inset: Stern-Volmer graphs of fluorescence quenching

Analysing the correlation between the fluorescent signal of the studied samples and the serotonin concentration, we observe that serotonin interaction with the double-stranded DNA molecules displays the most interesting dynamics. 
FARMACIA, 2019, Vol. 67, 2

The fluorescent signal quenching of the DNA-EB compound, related to the DNA-serotonin interaction, has been significantly higher, compared to melatonin $(p<0.001)$ and tryptophan $(p<0.001)$, respectively. Analysing the dynamics of the fluorescent signal quenching processes, we may argue that melatonin, serotonin and tryptophan displayed a similar behaviour, registering close values of fluorescence intensities.

The experimental results highlighted a dramatic decrease of the fluorescent signal issued by the DNA-EB system, along with the increase of indole concentration added in the system. This proves the displacement of the EB molecules intercalated in the double-stranded DNA.

The dynamics of these biochemical processes has been statistically evaluated using the SPSS information program, calculating the Pearson coefficients characterising the obtained experimental results: DNA/ melatonin interaction - Pearson coefficient $r=-0.9517$; DNA/serotonin interaction - Pearson coefficient $r=$ -0.9839; DNA/tryptophan interaction - Pearson coefficient $r=-0.9574$.

As it can be seen, for all 3 studied indoles, there is a negative statistical correlation of the parameters. This result indicates a higher affinity of the indole molecules to form bonds with the double-stranded DNA structure through intercalation between the nitrogenous bases pairs.

The DNA-indoles interactions have been evaluated mathematically by computing the quenching constants of the fluorescent signal, using the Stern-Volmer equation:

$$
\mathrm{I}_{0} / \mathrm{I}=1+\mathrm{K}_{\mathrm{SV}}[\text { indole }]
$$

where, $\mathrm{I}_{0}=$ fluorescence intensities without indole, $\mathrm{I}=$ fluorescence intensities with indole, $\mathrm{K}_{\mathrm{SV}}=$ SternVolmer quenching constant, [indole] $=$ indole concentration

The indole concentration was graphically represented depending on the fluorescence intensities ratio in the absence and in the presence of indolic molecules (Io/I) and we obtained the Stern-Volmer graph (Figure 5 inset).

We observed an increase of the fluorescence quenching phenomenon for all 3 studied indole molecules, along with the increase of the indole concentration (melatonin, serotonin, tryptophan). The experimental results led to the following values of Stern-Volmer quenching constants $\left(\mathrm{K}_{\mathrm{SV}}\right)$ : Melatonin-DNA interaction: $\mathrm{K}_{\mathrm{SV}}=6.08 * 10^{-2}$; Serotonin-DNA interaction: $\mathrm{K}_{\mathrm{SV}}=$ $6.73 * 10^{-2}$; Tryptophan-DNA interaction: $\mathrm{K}_{\mathrm{SV}}=$ $6.44 * 10^{-2}$.

The Stern-Volmer plots for the DNA-indoles interactions are linear, which proves the correlation of the quenching processes of the DNA-EB system's fluorescence after the intercalation of the indoles in the DNA molecule. According to the literature, this indicates the intercalation of the indole derivatives between the bases pairs which constitute the double-stranded DNA structure.

The system's fluorescence quenching process has been assessed in terms of percentage. The literature states that a compound interacts through intercalation with the double-stranded DNA structure, if during the experiment a percentage decrease over $40 \%$ of the fluorescent signal issued by the DNA-EB system is recorded. The fluorescence intensity has been reported initially, when the system only contained the DNA-EB compound, and after the adding the melatonin solution when the EB molecules bound to the DNA structure have been replaced with the indole molecules and they intercalated between the DNA bases pairs. The system's fluorescence intensity decreased by $70.07 \%$, through the EB displacement by melatonin, showing a powerful intercalation of melatonin in the DNA structure. The fluorescence intensity of the DNA-EB system decreased by $48.66 \%$ after adding serotonin solution. This led to the displacement of the EB intercalated in the DNA structure; however, compared to melatonin (decrease by $70.07 \%$ ), the binding of the serotonin in the DNA structure is weaker.

After adding tryptophan solution in the system, the fluorescence intensity decreased by $63.17 \%$. This was consecutive to the displacement of EB intercalated between the DNA nitrogenous bases pairs by tryptophan. As such, the binding of tryptophan in the DNA structure is comparable with melatonin binding (decrease by $70.07 \%$ ), and more powerful, compared to serotonin (decrease by $48.66 \%$ ).

The comparative assessment of the 3 intercalation processes of the studied endogenous indoles in the double-stranded DNA structure reveals an interesting dynamics of the system's fluorescence intensity. We registered a dramatic fluorescence signal decrease due to the EB displacement, by melatonin, thus noticing the most powerful binding of melatonin, through intercalation in the DNA structure, almost equal with the one performed by tryptophan and a weaker binding mechanism being registered between DNA and serotonin $[6,32]$.

The assessment of the DNA-indoles binding constants by UV spectroscopy

The indoles-DNA interactions have been studied in vitro using a UV spectroscopic method in view of computing the binding constants of the indole molecules of the double-stranded calf thymus DNA. Absorption spectra of the DNA solution, at a constant concentration, have been registered in the presence of increasing levels of indoles.

The experimental data obtained following the in vitro spectroscopic UV evaluation of DNA-indoles interactions, for the employed DNA/indole molar ratios $(1: 1,2: 1,3: 1,4: 1,5: 1,6: 1,7: 1,8: 1,9: 1$, $10: 1)$ was registered. It was found that, after adding increasing concentrations of the indoles solutions to 
FARMACIA, 2019, Vol. 67, 2

the double-stranded calf thymus DNA, a concentration-dependant increase of the absorbance of the analysed samples has been detected for all studied endogenous substances (Figure 6).

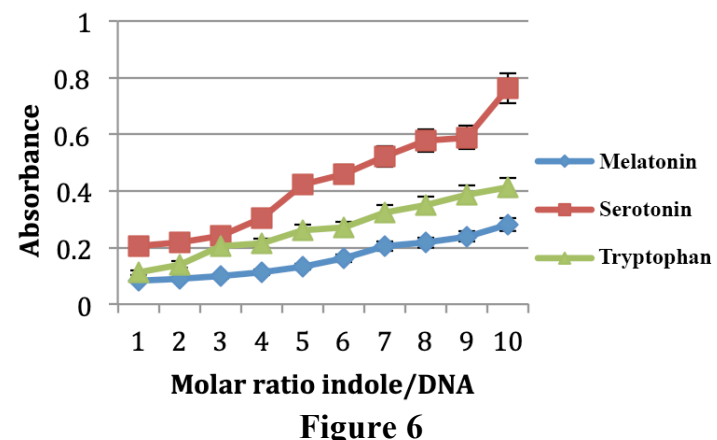

Dynamics of the absorbance of indole-DNA complexes depending on the indole-DNA molar ratio

The absorbance increase of the samples is determined by the intensification of the molecular planarity of the indole-DNA complex and by the decrease in the frequency of the collisions taking place between the solvent molecules (TRIS buffer solution $\mathrm{pH}=7$ ) and the molecules of the formed complex. These two phenomena are the effects of the intercalation mechanism of the indole molecules between the nitrogenous bases pairs of the double-stranded DNA molecule [21].

For the evaluation of the affinity between the indoles and DNA, it was calculated the binding constant $\mathrm{K}_{\mathrm{b}}$ for each of the formed complexes. For calculating $\mathrm{K}_{\mathrm{b}}$, it was used the equation:

$$
\frac{A_{o}}{A-A_{o}}=\frac{\varepsilon_{G}}{\varepsilon_{H-G}-\varepsilon_{G}}+\frac{\varepsilon_{G}}{\varepsilon_{H-G}-\varepsilon_{G}} \cdot \frac{1}{K_{b}[\text { indole }]}
$$

where, $\mathrm{A}_{0}=$ DNA absorbance in the absence of the indole, $\mathrm{A}=$ absorbance of the indole-DNA complex in the presence of different indole concentrations, $\varepsilon_{\mathrm{G}}=$ indole absorption coefficient, $\varepsilon_{\mathrm{H}-\mathrm{G}}=$ indoleDNA complex absorption coefficient, $\mathrm{K}_{\mathrm{b}}=$ binding constant , indole] $=$ indole concentration

The values Ao/A-Ao have been graphically represented depending on the concentration $1 /$ [indole] (Figure 7). The value of the melatonin-DNA complex affinity constant is higher than the one calculated for the serotonin-DNA complex. As such, the intercalation of serotonin in the DNA structure is not as simple as the melatonin intercalation. However, the serotonin affinity for the double-stranded DNA is significantly higher than the one of the intercalating agents per se. As for tryptophan, the binding constant is:

$$
\mathrm{K}_{\mathrm{b} \text { tryptophan-DNA }}=58.2 \times 10^{9} \mathrm{~L} / \mathrm{mol},
$$

which proves the existence of a stable intercalation process of the indole molecules in the DNA structure. The linear dependency of the studied parameters enables us to calculate the binding constants for the three indole compounds with the DNA: MelatoninDNA complex: $\mathrm{K}_{\mathrm{b}}=40.3 \times 10^{9} \mathrm{~L} / \mathrm{mol}$; Serotonin-DNA complex: $\mathrm{K}_{\mathrm{b}}=8.9 \times 10^{9} \mathrm{~L} / \mathrm{mol}$; Tryptophan-DNA complex DN: $\mathrm{K}_{\mathrm{b}}=58.2 \times 10^{9} \mathrm{~L} / \mathrm{mol}$ (Figure 7).

The binding constants of the three studied indole molecules in the double-stranded DNA structure are higher than the ones specified in literature for the classical intercalating agents: ethidium bromide-DNA complex: $\mathrm{K}_{\mathrm{b}}=7 \times 10^{7} \mathrm{~L} / \mathrm{mol}$; benzofuroindole - DNA complex: $\mathrm{K}_{\mathrm{b}}=1.3 \times 10^{5} \mathrm{~L} / \mathrm{mol}$; benzotienoindole DNA complex: $\mathrm{K}_{\mathrm{b}}=3.8 \times 10^{5} \mathrm{~L} / \mathrm{mol}$; proflavine DNA complex: $\mathrm{K}_{\mathrm{b}}=4.1 \times 10^{5} \mathrm{~L} / \mathrm{mol}$.

Therefore, we may conclude that the indoles affinity for DNA and the strength of their bonds is higher than the ones of the classical intercalating molecules in the DNA structure.


Graphical representation of the equations describing the indole-DNA binding process, consequently

allowing the calculation of $\mathrm{K}_{\mathrm{b}}$ indole-DNA

Following the direct in vitro evaluation using a spectrofluorometric method of DNA interaction with tryptophan, serotonin and melatonin, the experimental results highlighted a decrease of the fluorescent 
FARMACIA, 2019, Vol. 67, 2

signal of the assessed indoles, in the presence of DNA. This proves the existence, in vitro, of direct interactions between the molecules with indole structure and the double-stranded calf thymus DNA, which results in the quenching of the fluorescent signal of the indole molecules.

Correlating these experimental results with previously published data, it can be concluded that the quenching of the fluorescent signal of the studied indole molecules could be due to their intercalation in the double helix DNA structure. The fluorescent signal quenching in case of DNA-melatonin interaction has been significantly higher, compared to serotonin $(\mathrm{p}<$ $0.0001)$ and tryptophan $(\mathrm{p}<0.0001)$, respectively. The quenching of the florescent signals of DNAindoles systems was mathematically evaluated by calculating the Stern-Volmer constants $\left(\mathrm{K}_{\mathrm{SV}}\right)$. Interestingly, the $\mathrm{K}_{\mathrm{SV}}$ values for the three systems (DNA-melatonin, DNA-serotonin, DNA-tryptophan) have been extremely close from a numeric standpoint, which suggests the contribution, in the intercalation phenomenon of the indole moiety.

In conclusion, the conducted research studies proved that tryptophan, serotonin and melatonin directly interact, in vitro, with the double-stranded DNA through an indole-dependent intercalation process.

Further obtained experimental results showed that the binding of indole molecules to the DNA structure is made in the same way with the binding of ethidium bromide (EB), therefore through an intercalation mechanism, this leading to their "competing" with EB; a quenching process of DNA-EB complex fluorescence has been registered along with the increase of the indole concentration added in the system.

The results proved a higher affinity of indole molecules for bonding with the double-stranded DNA structure, through intercalation between the nitrogenous bases pairs.

The quenching of the DNA-EB fluorescent signal, as regards the DNA-indoles interactions, has been statistically significant, serotonin compared to melatonin ( $p<0.001)$ and to tryptophan ( $<<0.001)$, respectively. Analysing the dynamics of the fluorescent signal quenching processes and the obtained Stern-Volmer quenching constants $\left(\mathrm{K}_{\mathrm{SV}}\right)$, we may argue that melatonin, serotonin and tryptophan displayed a similar behaviour, which confirms the contribution, in the intercalation phenomenon of the studied compounds, of the indole moiety.

The literature indicates that a compound interacts through intercalation with the double-stranded DNA structure, if throughout the experiment it is registered a decrease of the fluorescent signal of the DNA-EB system by over $40 \%$. We obtained a decrease by $70.07 \%$ issued by the EB displacement by melatonin, thus noting the most powerful binding of melatonin, through intercalation in the DNA structure, almost equal with the tryptophan (decrease by $63.17 \%$ ) and in contrast with serotonin (decrease by $48.66 \%$ ).

After adding increasing concentrations of the studied indole solutions to the double-stranded calf thymus DNA, a proportional increase of the absorbance of the analysed samples has been registered for all studied substances.

The absorbance increase of the samples is determined by the intensification of the molecular planarity of the indole-DNA complex and by the decrease in the frequency of the collisions taking place between the solvent molecules and the molecules of the formed complex. These two phenomena are the effects of the intercalation mechanism of the indolic molecules between the nitrogenous bases pairs that constitute the double-stranded DNA molecule.

We calculated the binding constants for the three indole complexes with the DNA and proved the existence of powerful bonds between melatonin and tryptophan molecules and the DNA structure, as for serotonin, the $\mathrm{Kb}$ value revealed the formation of an intercalation-based link which is, nevertheless, weaker. The DNA binding constants of the 3 studied indole molecules have been compared to the literature data, the experimentally determined $\mathrm{Kb}$ values being higher than the ones of the classical intercalation agents.

\section{Conclusions}

The bioindoles affinity for DNA and the strength of the bonds established between these molecules is higher than the ones of the classical intercalating molecules in the DNA structure. Further studies will be accomplished for a better understanding of the bioindoles' nuclear mechanisms.

\section{References}

1. Almeida SMV, Lafayette EA, Gomes da Silva LPB, Amorim CAC, Oliveira TB, Ruiz ALTG, Carvalho JE, Moura RO, Beltrão EIC, Lima MCA, Synthesis, DNA binding, and antiproliferative activity of novel acridine-thiosemi-carbazone derivatives. Int J Mol Sci., 2015; 16: 13023-13042.

2. Arsene AL, Uivarosi V, Mitrea N, Drăgoi CM, Nicolae AC, The binding properties of some novel ruthenium (III) complexes with human serum transferrin. Biopolymers and cell, 2011; 27(2): 141-146.

3. Arsene AL, Uivarosi V, Mitrea N, Drăgoi CM, Nicolae $\mathrm{AC}$, In vitro studies regarding the interactions of some novel ruthenium (III) complexes with double stranded calf thymus deoxyribonucleic acid (DNA). Farmacia, 2016; 64(5): 712-716.

4. Barbu CG, Arsene AL, Florea S, Cardiovascular risk assessment in osteoporotic patients using osteoprotegerin as a reliable predictive biochemical marker. Mol Med Rep., 2017; 16(5): 6059-6067.

5. Bhattacharya Ali S, DNA binders in clinical trials and chemotherapy. Bioorg Med Chem., 2014; 22: 4506-4521. 
FARMACIA, 2019, Vol. 67, 2

6. Bi S, Zhang H, Qiao C, Sun Y, Liu C, Studies of interaction of emodin and DNA in the presence of ethidium bromide by spectroscopic method. Spectrochim Acta A., 2008; 69: 123-129.

7. Biswal S, Sahoo U, Sethy S, Kumar HKS, Banerjee M, Indole: the molecule of diverse biological activities. As J Pharm Clin Res., 2012; 5: 1-6.

8. Drăgoi CM, Mitrea N, Arsene AL, Ilie M, Nicolae AC, Jurkat E6.1 cell line studies regarding the effects of some bio-indols on the membrane fluidity. Farmacia, 2012; 60(1): 13-20.

9. Drăgoi CM, Mitrea N, Arsene AL, Nicolae AC, Ilie $\mathrm{M}$, In vitro effects of some bio-indoles on the transmembrane potential of Jurkat E6.1 limphoblasts. Farmacia, 2012; 60(2): 240-248.

10. Ginghină $\mathrm{O}$, Negrei C, Hudiță A, Ioana-Lavric V, Gălățeanu B, Dragomir S, Burcea Dragomiroiu GTA, Bârcă M, Nițipir C, Diaconu CC, In vitro impact of some natural compounds on HT-29 colorectal adenocarcinoma cells. Farmacia, 2017; 65(6): 947-953.

11. Grădinaru D, Mitrea N, Margină D, Arsene AL, Gruia V, Drăgoi CM, Nicolae AC, Borşa C, Gherasim P, Evaluation of serum osteocalcin in eldery patients with type-2 diabetes mellitus. Farmacia, 2009; 57(3): 331-338.

12. Gruia V, Aramă C, Mitrea N, Arsene AL, Grădinaru D, Drăgoi CM, The HPLC plasmatic profile of some fat-soluble antioxidant micronutrients (all-trans-retinol, $\alpha$-tocopherol, coenzime Q10) in diabetic and dyslipidemic patients. Farmacia, 2009; 57(5): 630-638.

13. Gurkan-Alp AS, Mumcuoglu M, Andac CA, Dayanc E, Cetin-Atalay R, Buyukbingol E, Synthesis, anticancer activities and molecular modeling studies of novel indole retinoid derivatives. Eur J Med Chem., 2012; 58: 346-354.

14. Hovanet MV, Dociu N, Dinu M, Ancuceanu R, Morosan E, Oprea E, A comparative physico-chemical analysis of Acer platanoides and Acer pseudoplatanus seed oils. Revista de Chimie, 2015; 66 (7): 987-991.

15. Lafayette EA, Almeida SMV, Pitta MGR, Beltrão EIC, Silva TG, Moura RO, Pitta IR, Carvalho Júnior LB, Synthesis, DNA binding and topo-isomerase I inhibition activity of thiazacridine and imidazacridine derivatives. Molecules, 2013; 18: 15035-15050.

16. Lafayette EA, de Almeida SMV, Cavalcanti Santos RV, de Oliveira JF, Amorim CADC, da Silva RMF, Pitta MGDR, Pitta IDR, de Moura RO, de Carvalho Júnior LB, de Melo Rêgo MJB, de Lima MDCA, Synthesis of novel indole derivatives as promising DNA-binding agents and evaluation of antitumor and antitopoisomerase I activities. Eur J Med Chem., 2017; 136: 511-522.

17. Marinescu S, Florescu IP, Giuglea C. et al. Free tissue transfer in hand surgery - essential step in hand transplantation. Chirurgia 2012; 107(1): 79-88.

18. Negreş S, Zanfirescu A, Ionică FE, Moroşan E, Velescu BŞ, Şeremet OC, Zbârcea CE, Ştefănescu E, Militaru M, Arsene AL, Margină DM, Uncu L, Scutari C, Chiriță C, Pharmacotoxicological screening on new derivatives of beta-phenylethylamine, potential agonists of beta3- adrenergic receptors. Rom J Morph Embry., 2016; 57(3): 969-978.

19. Nicolae AC, Drăgoi CM, Ceaușu I, Poalelungi C, Iliescu D, Arsene AL, Clinical implications of the indolergic system and oxidative stress in physiological gestational homeostasis. Farmacia, 2015; 63(1): 46-51.

20. Oniga S, Palage M, Araniciu C, Marc G, Oniga O, Vlase L, Prisăcari V, Valica V, Curlat S, Uncu L, Design, synthesis, molecular docking and antibacterial activity evaluation of some novel norfloxacin analogues. Farmacia, 2018; 66(6): 1048-1058.

21. Palchaudhuri R, Hergenrother PJ, DNA as a target for anticancer compounds: methods to determine the mode of binding and the mechanism of action. Curr Opin Biotechnol., 2007; 18: 497-503.

22. Qiao C, Bi S, Sun Y, Song D, Zhang H, Zhou W, Study of interactions of anthraquinones with DNA using ethidium bromide as a fluorescence probe. Spectrochim Acta A., 2008; 70: 136-143.

23. Rescifina A, Zagni C, Varrica MG, Pistara V, Corsaro A, Recent advances in small organic molecules as DNA intercalating agents: synthesis, activity and modelling. Eur J Med Chem., 2014; 74: 95-115.

24. Sharma V, Kumar P, Pathak D, Biological importance of the indole nucleus in recent years: a comprehensive review. J Heterocycl Chem., 2010; 47: 491-502.

25. Shimazakia Y, Yajimab T, Talanic M, Yamauchib O, Metal complexes involving indole rings: Structures and effects of metal-indole interactions. Coord Chem Rev., 2009; 253: 479-492.

26. Sordet $\mathrm{O}$, Solier S, Topoisomerases and Apoptosis, in: Y. Pommier (Ed.), DNA Topoisomerases and Cancer, Springer, New York, 2012.

27. Sravanthi TV, Manju SL, Indoles - A promising scaffold for drug development. Eur J Med Chem., 2016; 91: 1-10.

28. Voiculescu SE, Le Duc D, Roşca AE, Zeca V, Chiţimuş DM, Arsene AL, Drăgoi CM, Nicolae $\mathrm{AC}$, Behavioral and molecular effects of prenatal continuous light exposure in the adult rat. Brain Res., 2016; 1650: 51-59.

29. Wang X, Yan M, Wang Q, Wang H, Wang Z, Zhao J, Li J, Zhang Z, In vitro DNA-binding, anti-oxidant and anticancer activity of indole-2-carboxylic acid dinuclear copper (II) complexes. Molecules, 2017; 22: 171-183.

30. Wei SL, Zhao LX, Cheng XL, Lin JM, Determination of melatonin in rat pineal gland and drug with flowinjection chemiluminescence. Chin J Chem., 2007; 25: 535-541.

31. Yumin S, Jingwan K, Zhihua W, Xiaoquan L, Jinzhang G, Liufang W, Study on the interactions between $\mathrm{CuL}$ and Morin with DNA. J Inorg Biochem., 2002; 91: 470-474

32. Zhu J, Chen L, Dong Y, Li J, Liu X, Spectroscopic and molecular modelling methods to investigate the interaction between 5-Hydroxymethyl-2-furfural and calf thymus DNA using ethidium bromide as a probe. Spectrochim. Acta A Mol Biomol Spectrosc., 2014; 124: 78-83 